\title{
New Aryl Derivatives of Acridine with Poly (ADP- Ribose) Polymerase 1 Inhibitory Activity: A Molecular Modeling Approach
}

\author{
Sayantani Karmakar ${ }^{1}$, Rita Ghosh ${ }^{2 *}$ \\ ${ }^{1,2}$ Department of Biochemistry and Biophysics, University of Kalyani, Kalyani-741235, West Bengal, India
}

\begin{abstract}
Poly (ADP-ribose) polymerase 1 (PARP1) is a nuclear enzyme, involved in DNA repair and transcriptional regulation of genes that regulates cell survival and death. PARP1 inhibitors are therefore, often used with other drugs to enhance cell killing in cancer therapy. We present here our findings on the PARP1 inhibitory activities of some novel aryl acridines from molecular modelling studies. Like other established inhibitors of PARP1, these aryl acridines also bind to the nicotinamide adenine dinucleotide (NAD+) binding pocket of PARP1. They interact through non covalent ionic interactions and are capable of forming inter-molecular hydrogen bonds with several amino acids in this site; this includes all the important amino acid residues necessary for the catalytic activity of PARP1. The findings are important as this is the first report showing some acridine compounds as novel PARP1 inhibitors.
\end{abstract}

Keywords: PARP1, NAD ${ }^{+}, 9$ aryl acridines, Molecular Modeling, Molecular Docking

\section{Introduction}

Poly (ADP-ribose) polymerase 1 (PARP1) is a nuclear enzyme, involved in DNA repair and transcriptional regulation of genes that regulates cell survival and death [1]. PARP1 response is provoked by genotoxic stress on DNA. It senses breaks in DNA and catalyses the addition of ADPribose onto different nucleosomal proteins and also onto itself, as linear or branched PAR chains using $\mathrm{NAD}^{+}$as its substrate [2]. The poly (ADP-ribosyl)ation of the histone proteins helps to draw away the nucleosomal proteins from DNA to facilitate DNA repair [3]. Inhibition of PARP1 activity thus sensitizes cells to killing by different damaging agents $[4,5]$. PARP1 inhibitors are therefore important in cancer chemotherapeutics [6].

The primary structure of PARP1 consists of 1014 residues organized in 3 functionally distinct domains: i) DNA binding $\mathrm{N}$ terminal domain, ii) auto-modification domain for ADP ribosylation and iii) catalytic domain at the $\mathrm{C}$ terminal region [7]. The catalytic site consists of residues 654 to 1014 and includes importantly the residues Tyr710, Gln763, Asp766, Asn767, Asp770, Trp861, His862, Gly863, Ser864, Arg878, Ile879, Ala880, Gly888, Tyr889, Met890, Gly894, Tyr896, Phe897, Ala898, Lys903, Ser904, Tyr907, Asn987, Glu988 and Tyr989 [8]. Ruf et al. predicted that the putative $\mathrm{NAD}^{+}$binding site resides in the catalytic region [9]. Within the catalytic site, the $\mathrm{NAD}^{+}$binding pocket is lined by the residues His862, Gly863, Tyr896, Phe897, Ala898, Lys903, Ser904, Tyr907 and Glu988 [10]. Different PARP1 inhibitors bind at the $\mathrm{NAD}^{+}$binding pocket to exert their inhibitory effect [10].

Acridine derivatives are known to interact with different key enzymes [11, 12] to exhibit antitumor activity [13-15]. Particularly important are the derivatives at C 9 position $[16$, 17]. The biological activities of phenyl-derivatives at $\mathrm{C} 9$ position were so far less explored. From our earlier works the biological importance of some aryl derivatives of acridine are already documented $[18,19]$ and the antitumor action have been demonstrated in different cancer cell lines as well as in animal model [20]. Aryl acridine derivatives can also potentiate cell killing by other agents (our unpublished results). We therefore wanted to explore whether any of these derivatives can have PARP1 inhibitory activity.

We present here the molecular modeling studies on interaction of some 9 aryl acridine derivatives with chicken PARP1. Human PARP1 is a homo-dimer that shares strong sequence similarity with chicken PARP1 $(87 \%)$. The amino acid residues around the active site of PARP1 from both the species are perfectly conserved [21]. The monomeric chicken PARP1 is most often used for studying the inhibitory potentials of different drugs [8-10]. Human and chicken numbering of amino acids differs by three [9]; since human PARP1 is the drug target, the human numbering is used conventionally in all reports. Our preliminary findings indicate that these acridines are likely to exert inhibitory effect on PARP1 by blocking the binding of $\mathrm{NAD}^{+}$at the catalytic region of PARP1.

\section{Materials and methods}

\subsection{Generation of three dimensional structures of ligands}

The three dimensional coordinates of 9 aryl derivatives of acridine were generated and optimized in three dimensional space using the program ACD/ChemSketch (http://www.acdlabs.com/download/chemsk.html) and PyMOL 7.2 [22]. The programs generate the backbone coordinates of the molecules first and then add the side chain atoms. In order to relieve the steric strain in the molecule, the entire molecule was energy minimized. The energy minimization was done using the Conjugate Gradient (CG) algorithm with CHARMm force-fields until the structures reached the final energy derivative of $0.001 \mathrm{kcal} /$ mole. A total of 500 steps of energy minimizations were performed for the 9 aryl derivatives of acridine. The final energy minimized structures of the 9 aryl derivatives of acridine were used for further docking analysis. The coordinates of 


\section{International Journal of Science and Research (IJSR) \\ ISSN (Online): 2319-7064 \\ Index Copernicus Value (2013): 6.14 | Impact Factor (2014): 5.611}

chicken PARP1 protein were extracted from Protein Data Bank (PDB ID: 3PAX) [10]. The structures of the ligands and the protein were saved separately. The structure of PARP1 protein from chicken was energy minimized using CG in 200 cycles until the structure reached the final energy derivative of $0.001 \mathrm{kcal} /$ mole. The backbone of the protein was kept fixed in order to keep the overall secondary structure of the protein intact. All the energy minimizations were done using the program ACCELERYS DISCOVERY STUDIO 2.5 with CHARMm force field [23]. These energy minimized structures were then used for molecular docking analyses.

\subsection{Docking of the ligand with PARP1}

The docking of the ligands with the PARP1 protein was performed with Autodock 4.2 software [24]. The software utilizes the LGA implemented therein. The grid size was set to 126 (maximum grid size) along the $\mathrm{X}, \mathrm{Y}$ and $\mathrm{Z}$ axis with $0.375 \AA$ grid spacing. In order to get a comprehensive result, the ligands and the receptor PARP1 were subjected to another two rounds of docking using Patchdock server [25] and the program GOLD [26] using the default parameters. Patchdock uses surface complimentarity method to find the docking poses. The program searches for the presence of binding clefts on the surfaces of the ligands and receptors. On the other hand, GOLD uses Genetic Algorithm to find the docking poses. GOLD uses various combinations of bindings between the receptor and the ligands and calculates the binding interactions. We used these different protocols to find the docking poses such that we get a realistic picture of the docking interactions between the ligands and the PARP1.

From the Autodock results, the lowest binding energy conformation was selected out of the 10 different conformational outputs and analyzed. From the program GOLD, the docked complexes that yielded the best Goldscore and Chemscore were selected. The best docked conformations so formed from the above mentioned software tools were again energy minimized by CG algorithm using the program ACCELERYS DISCOVERY STUDIO 2.5 with CHARMm force field until the structures reached the final energy derivative of $0.001 \mathrm{kcal} / \mathrm{mole}$ in order to relieve bad contacts [23].

\section{Results}

The 9 aryl acridine derivatives used in our study have the capacity of binding to the NAD ${ }^{+}$binding pocket of PARP1. Figure 1 represents the binding of $\mathrm{ACPH} 1, \mathrm{ACPH} 3$ and $\mathrm{ACPH} 4$ at the $\mathrm{NAD}^{+}$binding pocket of chicken PARP1. The association of these aryl derivatives of acridine at the $\mathrm{NAD}^{+}$binding pocket is shown from three different orientations.

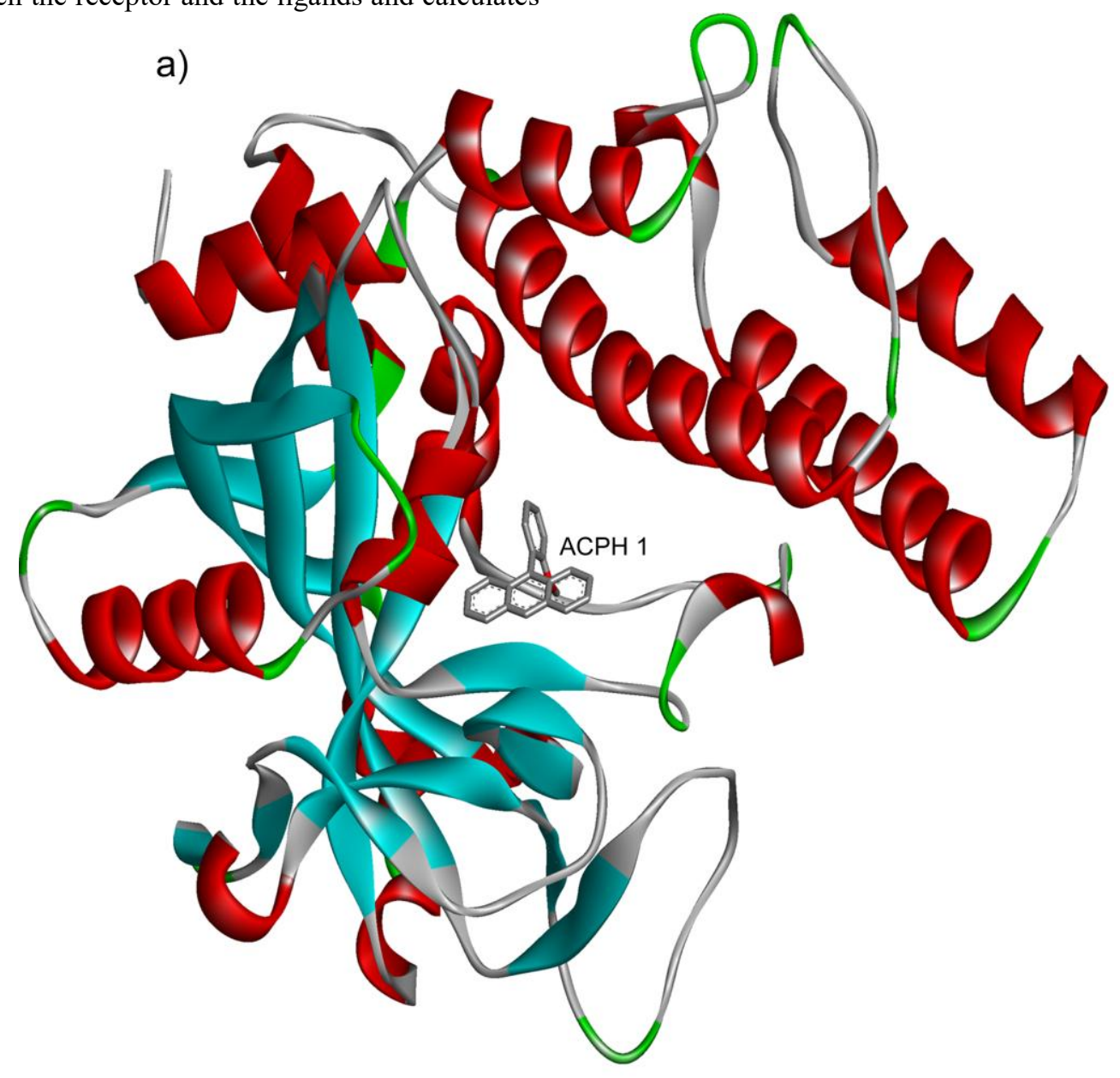

Volume 4 Issue 12, December 2015 


\section{International Journal of Science and Research (IJSR) \\ ISSN (Online): 2319-7064}

Index Copernicus Value (2013): 6.14 | Impact Factor (2014): 5.611
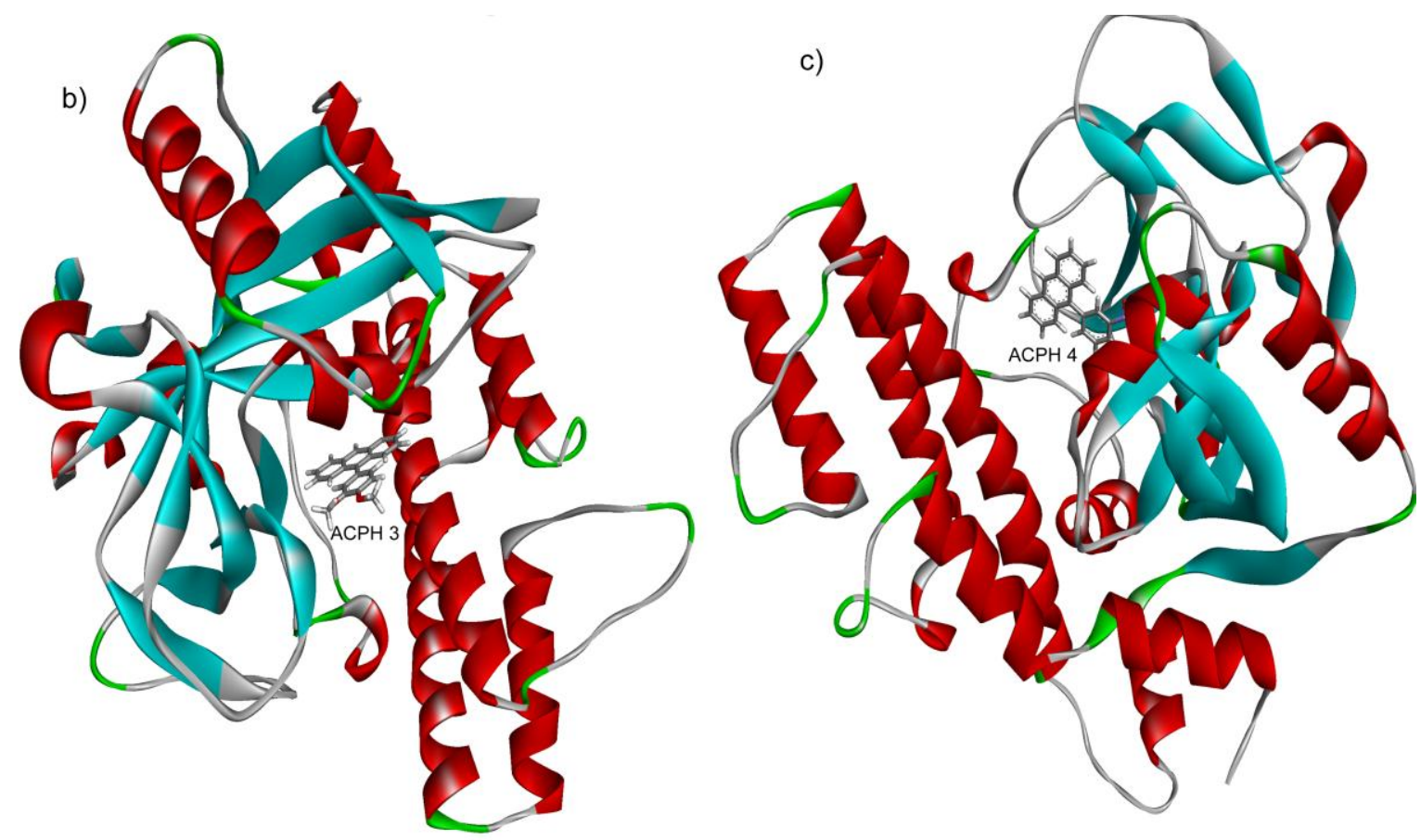

Figure 1: The binding of 9 aryl acridine derivatives (a) ACPH 1, (b) ACPH 3 and (c) ACPH 4 with chicken PARP1 is shown from three different orientations. The protein is shown in solid ribbon form (secondary type) and the aryl acridine derivatives are shown in stick form

Table 1: The ionic interactions and hydrogen bonding involved when different derivatives of acridine interact with chicken PARP1

\begin{tabular}{|c|c|c|}
\hline $\begin{array}{c}\text { 9-aryl } \\
\text { acridine } \\
\text { derivatives }\end{array}$ & $\begin{array}{l}\text { Name of the amino acids } \\
\text { involved in ionic interaction }\end{array}$ & $\begin{array}{l}\text { Amino acids } \\
\text { involved in } \\
\text { hydrogen bond } \\
\text { interaction }\end{array}$ \\
\hline АСРН 1 & $\begin{array}{llr}\text { Trp861, } & \text { His862, } & \text { Gly863, } \\
\text { Ser864, } & \text { Gly894, } & \text { Ile895, } \\
\text { Tyr896, } & \text { Phe897, } & \text { Ala898, } \\
\text { Lys903, } & \text { Ser904, } & \text { Tyr907, } \\
\text { Glu988. } & & \\
\end{array}$ & Tyr907 \\
\hline АСРН 2 & $\begin{array}{lll}\text { Gln763, } & \text { Asn767, } & \text { Trp861, } \\
\text { His862, } & \text { Gly863, } & \text { Ser864, } \\
\text { Arg865, } & \text { Tyr889, } & \text { Met890, } \\
\text { Phe891, } & \text { Tyr896, } & \text { Phe897, } \\
\text { Ala898, Lys903, Ser904, } & \text { Ser } \\
\text { Tyr907, His909, Leu 984, } & \text { 989, Tyr989. } \\
\text { Asn987, Glu988, }\end{array}$ & $\begin{array}{l}\text { Lys903, } \\
\text { Glu988 }\end{array}$ \\
\hline АСРН 3 & $\begin{array}{lcc}\text { Gln 763, } & \text { Asp766, } & \text { Trp861, } \\
\text { His862, } & \text { Gly863, } & \text { Leu877, } \\
\text { Arg878, } & \text { Ile879, } & \text { Ala880, } \\
\text { Gly888, } & \text { Tyr889, } & \text { Met890, } \\
\text { Gly894, } & \text { Ile895, } & \text { Tyr896, } \\
\text { Phe897, Ala898, } & \text { Lys903, } \\
\text { Ser904, Tyr907, Glu988 }\end{array}$ & Tyr907, Glu988 \\
\hline АСРН 4 & $\begin{array}{lll}\text { Gln763, } & \text { Asp766, } & \text { Trp861, } \\
\text { His862, } & \text { Gly863, } & \text { Gly888, } \\
\text { Tyr889, } & \text { Met890, } & \text { Tyr896, } \\
\text { Phe897, } & \text { Ala898, Lys903, } & \text { Ly98, } \\
\text { Ser904, Tyr907,Glu98 }\end{array}$ & Ser904, Tyr907 \\
\hline
\end{tabular}

The amino acid residues within $5 \AA$ distance from each of the acridine derivatives are likely to undergo ionic interaction; these are shown in table 1. Some of the residues at this site are important for the catalytic function and established inhibitors specifically interact with them to exert their inhibitory role. All the acridine derivatives are found to interact with these residues; these are indicated in bold in table 1 . The presence of nitro and methoxy groups in the derivatives makes them capable of forming non covalent interactions with PARP1. The amino acid residues with which these derivatives formed $\mathrm{H}$ bonds at the $\mathrm{NAD}^{+}$ binding pocket are also shown in the same table (table 1). A close up view of $\mathrm{ACPH} 2$ bound to the $\mathrm{NAD}^{+}$binding pocket is shown in figure 2 . The amino acids with which $\mathrm{ACPH} 2$ undergo interactions are shown in this figure. ACPH 2 also forms two hydrogen bonds, one with NZ2 atom of Lys 903 and the other with OE2 atom of Glu988 with bond distances of $2.30 \AA$ and $2.70 \AA$ respectively; these are also indicated in this figure. 


\section{International Journal of Science and Research (IJSR) \\ ISSN (Online): 2319-7064}

Index Copernicus Value (2013): 6.14 | Impact Factor (2014): 5.611

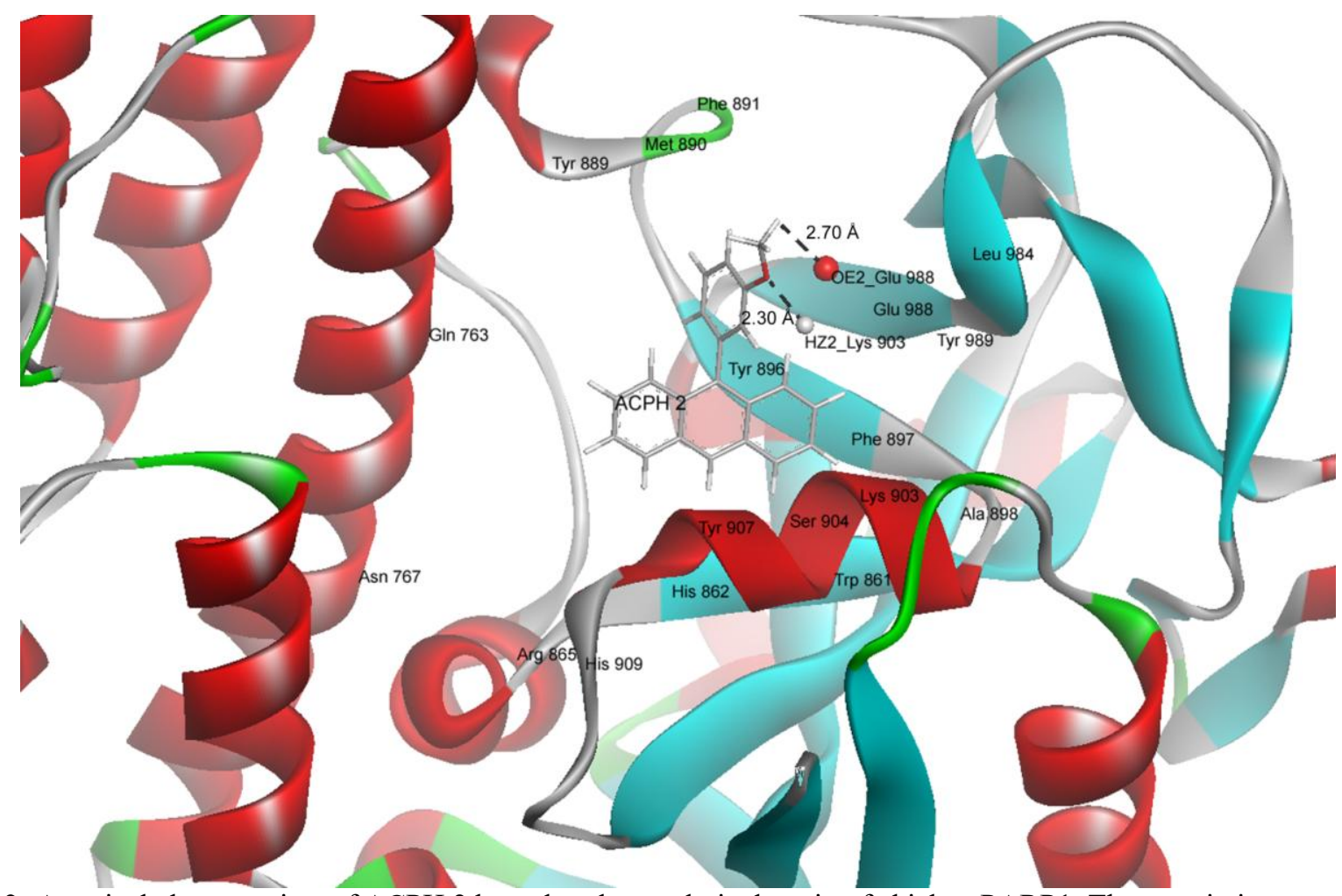

Figure 2: A typical close up view of ACPH 2 bound to the catalytic domain of chicken PARP1. The protein is represented in solid ribbon form (secondary type) and the derivative ACPH 2 is represented in stick form. The hydrogen bonds are represented by the black dotted lines.

\section{Discussion}

The catalytic site of PARP1 contains two important locations - i) the place where the ADP ribose moiety joins to form the PAR chain, known as the acceptor site and ii) the location of $\mathrm{NAD}^{+}$binding, known as the donor site. Most of the PARP1 inhibitors developed till date like 3MBA, 4ANI, PD 127863, NU1025 mimic the $\mathrm{NAD}^{+}$moiety and binds to the $\mathrm{NAD}^{+}$binding pocket to block the binding of $\mathrm{NAD}^{+}$to the enzyme thereby inhibiting the PARP1 activity [27] The residues Gly863, Lys903, Ser904, Tyr907 and Glu988 at the $\mathrm{NAD}^{+}$binding pocket are significant for the catalytic activity of the enzyme [10]. Almost all the established PARP1 inhibitors interact with these amino acids [10]; our acridine derivatives too, interacted with all these amino acids and additionally with some other amino acids at this site.

When NAD ${ }^{+}$binds as a precursor to PARP1, it undergoes $\mathrm{H}$ bonding with Ser904. Inhibitors like 3MBA, 4ANI, PD 127863 , NU1025 prevent the binding of $\mathrm{NAD}^{+}$to PARP 1 by forming $\mathrm{H}$ bond with Ser904 [28]. PD 127863 undergoes hydrogen bond with Lys 903 which increases its binding specificity [10]. ACPH 4 undergoes H bonding with Ser904, all the other derivatives (ACPH 1, 2, 3) also undergoes ionic interaction with Ser904. Thus, these acridines too, might prevent the association of $\mathrm{NAD}^{+}$to PARP1. Another important amino acid is Tyr907 that is responsible for forming the wall of the $\mathrm{NAD}^{+}$binding pocket [10]. Mutation of Tyr907 with Asparagine reduces its activity to $1.1 \%$ [29]. Inhibitors of PARP1 like 4ANI, NU1025, NU1085 undergo $\mathrm{H}$ bonding with Tyr907 and Gly863 [10, 28]. The derivatives ACPH 1, ACPH 3 and ACPH 4 also undergo $H$ bonding with Tyr907 thereby strongly indicating their inhibitory potential.

There is a great similarity between ADP ribosylating activity catalyzed by PARP and that of some bacterial toxins like pertussis toxin, diptheria toxin, cholera toxin etc, which also joins ADP-ribose units to form polymers [30]. It has been demonstrated for these toxins that the glutamic acid residue at their catalytic site is important for the ADP-ribosylating activity, responsible for the polymer formation [30]. The glutamic acid residue at the catalytic site is conserved for PARP proteins as well as for the toxins [30]. In case of human PARP1, Glu988 is responsible for this function. Mutation of this residue strongly affected the function of the enzyme and its activity drops down to $0.2 \%$ of that in the wild type after its mutation to Tyrosine or Alanine [29].Our findings revealed that all the derivatives of $\mathrm{ACPH}$ interacted with Glu988, while ACPH 2 and ACPH 3 also formed $\mathrm{H}$ bond with this amino acid.

\section{Conclusion}

Our preliminary findings from molecular modeling studies revealed that these novel acridine derivatives are likely to act as PARP1 inhibitors by binding at the $\mathrm{NAD}^{+}$binding pocket in its catalytic domain. Different acridine derivatives are known for their varied biological activities, however, so far none are known as PARP inhibitors. The established inhibitors of PARP1 generally contain a nicotinamide moiety that allows them to mimic $\mathrm{NAD}^{+}$and compete for binding at this site. Our findings are important as this is the first report showing that aryl acridines too, can bind at the $\mathrm{NAD}^{+}$pocket of PARP1 to exert its inhibitory action. Further studies are needed to establish the PARP1 inhibitory 


\section{International Journal of Science and Research (IJSR) \\ ISSN (Online): 2319-7064 \\ Index Copernicus Value (2013): 6.14 | Impact Factor (2014): 5.611}

activity of these acridines. Considering the importance of PARP1 inhibitors as chemotherapeutic agent, these acridine derivatives could be potential drug candidates for cancer therapy.

\section{Acknowledgements}

The authors acknowledge the kind assistance of Dr. Angshuman Bagchi, Coordinator BIF centre, for help and the use of the Bioinformatics Facility, University of Kalyani for this work. Authors also acknowledge financial assistance from University of Kalyani, Kalyani and DST-PURSE, Govt. of India. Sayantani Karmakar is supported with fellowship from UGC-BSR, Govt of India.

\section{References}

[1] Amé JC, Spenlehauer C, De Murcia G. The PARP superfamily. BioEssays 2004; 26: 882-893.

[2] Kaur J and Singh P. Acridine derivatives: a patent review (2009-2010). Expert Opin Ther Pat 2011; 21(4): 437454.

[3] Muthurajan UM, Hepler MRD, Hieb AR, et al. Automodification switches PARP-1 function from chromatin architectural protein to histone chaperone. Proc Natl Acad Sci 2014;111(35): 12752-12757.

[4] Bendell J, O'Reilly EM, Middleton MR, Chau I, et al. Phase I study of olaparib plus gemcitabine in patients with advanced solid tumours and comparison with gemcitabine alone in patients with locally advanced metastatic pancreatic cancer. Ann Oncol 2015; 26(4):80411.

[5] Davar D, Beumer JH, Hamieh L, et al. Role of PARP inhibitors in cancer biology and therapy. Curr Med Chem 2012; 19(23): 3907-3921.

[6] Yap TA, Sandhu SK, Carden CP. de Bono JS. Poly (ADP-Ribose) polymerase (PARP) inhibitors: Exploiting a synthetic lethal strategy in the clinic. CA Cancer J Clin $2011 ; 61: 31-49$

[7] Jagtap P and Szabo C. Poly (ADP-ribose) polymerase and the therapeutic effects of its inhibitors. Nat Rev Drug Discov 2005; 4: 421-440.

[8] Costantino G, Macchiarulo A, Camaioni E, et al. Modeling of poly(ADP-ribose)polymerase (PARP) inhibitors. Docking of ligands and quantitative structureactivity relationship analysis. J Med Chem 2001; 44: 3786-3794.

[9] Ruf A, De Murcia JM, De Murcia G, et al. Structure of the catalytic fragment of poly (ADP-ribose) polymerase from chicken. Proc Natl Acad Sci 1996; 93: 7481-7485.

[10] Ruf A, De Murcia G, Schulz GE. Inhibitor and NAD ${ }^{+}$ binding to Poly (ADP-ribose) polymerase as derived from crystal structures and homology modelling. Biochem 1998; 37: 3893-3900.

[11] Taliawi GME, Ali EI, Hegazy GH, et al. Computer aided design, Synthesis and biological evaluation of novel acridine derivatives a topoisomerase I inhibitors. J Am Sci 2010; 6(11):148-158.

[12] Harrison RJ, Gowan SM, Kelland LR, et al. Human telomerase inhibition by substituted acridine derivatives. Bioorg Med Chem Lett 1999; 9: 2463-2468.

[13] Demeunynck M. Antitumor acridines. Expert Opin Ther Pat 2004; 14(1):55-70.
[14] Wang W, Ho WC, Dicker DT, et al. Acridine derivatives activate p53 and induce tumor cell death through bax. Cancer Biol Ther 2005; 4:8: 893-898.

[15] Cholewiński G, Dzierzbicka K, Kołodziejczyk AM. Natural and synthetic acridines/acridones as antitumor agents: their biological activities and methods of synthesis. Pharmacol Rep 2011; 63: 305-336.

[16] Bacherikov VA, Chang JY, Lin YW, et al. Synthesis and antitumor activity of 5-(9-acridinylamino)anisidine derivatives. Bioorg Med Chem 2005; 13: 6513-6520.

[17] Kimura A. Acridine derivatives IV [1]. Synthesis, molecular structure and antitumor activity of novel 9anilino -2, 3- methylenedioxyacridines. J Heterocycl Chem 1992; 29: 73-79.

[18] Bhowmik S, Bagchi A, Ghosh R. Molecular modeling studies on some 9-arylacridine derivatives to elucidate their possible roles in topoisomerase 1 inhibition. Int $\mathrm{J}$ Integr Biol 2008; 2(1): 8-14

[19] Ghosh R, Bhowmik S, Bagchi A, et al. Chemotherapeutic potential of 9-phenyl acridine: biophysical studies on its binding to DNA. Eur Biophys J 2010; 39:1243-1249

[20] Ghosh R, Bhowmik S, Guha D. 9-Phenyl acridine exhibits antitumour activity by inducing apoptosis in A375 cells. Mol Cell Biochem 2012; 361(1-2):55-66.

[21] Kinoshita T, Nakanishi I, Warizaya M, et al. Inhibitorinduced structural change of the active site of human poly(ADP-ribose) polymerase. FEBS Lett 2004; 556: 4346.

[22] Lill MA and Danielson ML. Computer-aided drug design platform using PyMOL. J Comput Aided Mol Des 2011; 25: 13-19.

[23] Brooks BR, Bruccoleri RE, Olafson BD, et al. CHARMM: A program for macromolecular energy minimization and dynamics calculations. J Comp Chem 1983; 4:187-217.

[24] Morris GM, Goodsell DS, Halliday RS, et al. Automated docking using a Lamarckian genetic algorithm and an empirical binding free energy function. J Comput Chem 1998; 19:1639-1662.

[25] Duhovny DS, Inbar Y, Nussinov R, et al. PatchDock and SymmDock: servers for rigid and symmetric docking. Nuc Acids Res 2005; 33 Web server issue W363-W367, doi: $10.1093 /$ nar/gki481.

[26] Jones G, Willett P, Glen RC, et al. Development and validation of a genetic algorithm for flexible docking. $\mathrm{J}$ Mol Biol 1997; 267(3):727-748.

[27] Peralta-Leal A, Rodríguez-Vargas JM, Aguilar-Quesada $\mathrm{R}$, et al. PARP inhibitors: New partners in the therapy of cancer and inflammatory diseases. Free Radic Biol Med 2009; 47: 13-26.

[28] Ruf A, Ve Âronique R, De Murcia G, et al. The mechanism of the elongation and branching reaction of poly (ADP-ribose) polymerase as derived from crystal structures and mutagenesis. J Mol Biol 1998; 278: 57-65.

[29] Curtin NJ. PARP inhibitors and cancer therapy, in: A. Bürkle (Ed.), Poly(ADP-Ribosyl)ation, Landes Bioscience and Springer Science + Business Media, 2006; pp. $218-233$.

[30] Marsischky GT, Wilson BA, Collier RJ. Role of glutamic acid 988 of human poly-ADP-ribose polymerase in polymer formation. Evidence for active site similarities to the ADP-ribosylating toxins. J Biol Chem 1995; 270(7): 3247-3254 